\title{
Impact of sea level rise on the land cover structure in Southeast
} Asia

\author{
Piotr Michalak, Angelina Patsili, Olga Carmen and Carsten Keßler \\ pmicha19@student.aau.dk, apatsi19@student.aau.dk, osteau19@student.aau.dk, kessler@plan.aau.dk
}

Department of Planning, Aalborg University, Copenhagen, Denmark

\begin{abstract}
Sea-level rise in Southeast Asia is a consequence of climate change that will affect almost all coastal countries in the region. The results of this phenomenon may have severe consequences, from problems with food production, through mass migration of people, to the threat to unique ecological areas. Hence, the main aim of this research was to investigate the impact of sea level rise on the land cover structure in the region and how it may affect the situation of the countries in the region. For this purpose, GlobCover 2009 data and projections of sea level rise by one meter were used and a multiband raster image was created containing information about the land cover class, country and whether the area is threatened by sea level rise. All calculations have been made on the raster prepared in this way, which shows that $4.4 \%$ of South East Asia's areas are at risk of rising sea levels. Finally, the ratio was calculated for each land cover class. This showed the unusual vulnerability of some of the classes to rising sea levels like irrigated croplands and urban areas.
\end{abstract}

Keywords: sea level rise, land structure, Southeast Asia

\section{Introduction}

Sea level rise is one of the biggest challenges facing modern civilization. It is estimated that by 2100 sea level may rise up to 1 meter (See Fig. 1), which will result in an unprecedented scale of climate migration (Rahmstorf et al., 2012). Southeast Asia is a region particularly vulnerable to rising sea levels because lowland and delta areas constitute a significant part of the region, which consists of eleven countries: Brunei, Cambodia, Indonesia, Laos, Malaysia, Myanmar, Philippines, Singapore, Thailand, East Timor and Vietnam. They are mostly developing countries with a large population and a long coastline. The countries of the region are extremely diverse in cultural, religious, and political terms.

As of 2021,673 million inhabitants $-8.58 \%$ of the total world population - live in Southeast Asia. The most populous countries in the region are Indonesia with 272 million inhabitants (over $22 \%$ of the region's population lives on the Indonesian Java), the Philippines with 112 million inhabitants and Vietnam with 96 million inhabitants. On the other end, in terms of population is East Timor, and Brunei with 1.2 and 0.4 million inhabitants, respectively. Population of the region continues to grow with an annual change of 1.06 percentage (IMF, 2016). The problem in the region is illustrated by the example of Jakarta, which is the first mega city threatened by flooding (Abidin et al., 2010).

Since early humans settled in the coastal regions, they have learned to adapt to changing conditions and the threats of floods and storms. Different protection strategies were used along the time, with some still in use today (Bollmann et al., 2010):

- adapting the buildings

- building coastal protection systems (dams, flood barriers etc.)

- migration (leaving the threatened areas)

- "wait and see" what's going to happen

The protection of low-lying areas against sea level rise, flooding and other phenomena related to climate change is an extremely complex and costly process. The Netherlands' case demonstrates that a small but developed and prosperous country, when facing such threats, is clearly capable to deal with it by following a long-term defence strategy, even though around one third of the country lies below sea level (Katsman et al., 2011). Germany is another example of investing a lot of money in coastal protection (Sterr, 2008). Most countries in Southeast Asia, however, do not have the 
economical capacity to protect the coastline on a comparable level.

In counteracting the effects of rising sea levels, it is necessary to know what areas are most vulnerable to flooding. This knowledge facilitates decisions on the protection of key areas or withdrawal in the case of less important areas (Thomsen et al., 2012). In addition, knowing the land structure of areas at risk of flooding, it is possible to make long-term strategic decisions, including increasing the share of agricultural areas in the higher located parts of the country to keep food production stable in the face of sea level rise (Chen et al., 2012).

Previous work on this topic has focused on the qualitative analysis of the susceptibility of the region's countries to sea-level rise (Rommel et al., 2008) and the analysis of specific cases (Mehvar et al., 2018). The purpose of this work was therefore to complement the work of other researchers and to conduct a quantitative analysis in Southeast Asia assuming a rise in sea level by 1 meter. The conducted research showed that on average 4.4 percent of the area of the region's countries can be flooded. Detailed results are presented below.

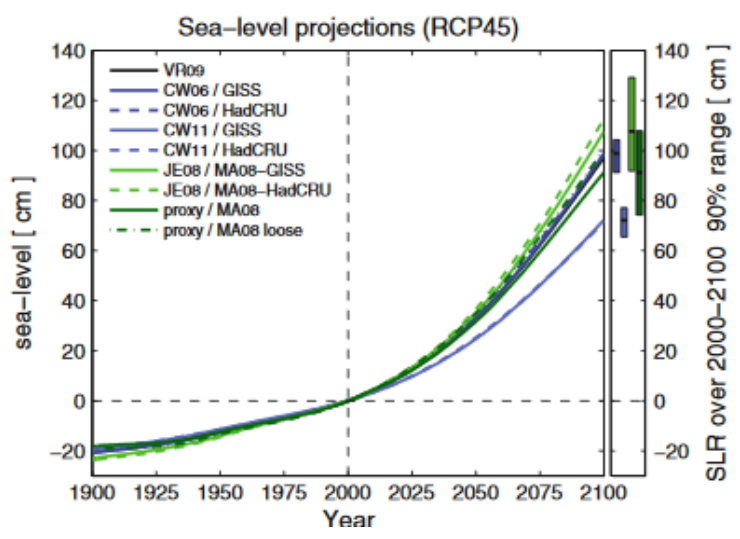

Figure 1: Projection of sea level rise to year 2100 [1].

\section{Materials and Methods}

The land cover maps were obtained from the European Space Agency database. The GlobCover 2009 project provides land cover maps at global scale, using remote sensing data from the $300 \mathrm{~m}$ MERIS sensor on the ENVISAT-1 satellite (ESA, 2020). Data on sea level rise have been acquired for a value of 1 meter from the Center for the Remote Sensing of ICE Sheets (Cresis, 2020) and were created on the basis of the digital elevation model and contains only two pixel values: 1 and 0 (True or False) which has the information whether the pixel will be affected by sea level rise or not. The spatial resolution of the dataset is 30 arcseconds. The last set of data used in the study were the borders of the countries and their exclusive economic zones (EEZ) of the countries of the region obtained from the Marine Regions database, created by the Vlaams Instituut voor de Zee (VLIZ, 2020).

To conduct the analysis, ArcGIS software and Python programming language were used to perform preprocessing and numeric operations

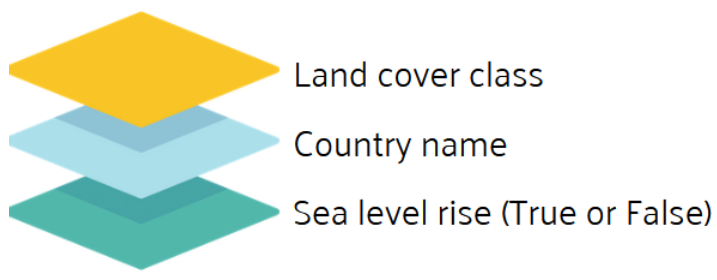

Figure 2: Information represented by each pixel in a multiband raster.

To be able to carry out quantitative analysis, it was necessary to calculate the area at risk of rising sea level, by country and by land cover type. To this end, it was necessary to transform the data and create a multispectral raster image containing information about the type of land cover, the country and the threat/or not of sea level rising for each pixel. The basic idea is illustrated in the Fig. 2. To achieve this, it was necessary to perform three steps. Firstly, the vector-based EEZ data was transformed to raster format with the name of the country in numerical form as pixel value. Then it was required to transform the data into Indonesian Datum 1974 equal area projection and resample the raster data to the GlobCover raster cell size which will allow relevant analyses to be carried out. Finally, the data was clipped to areas of interest and the composite raster band was created. The whole process is presented in Fig. 3.

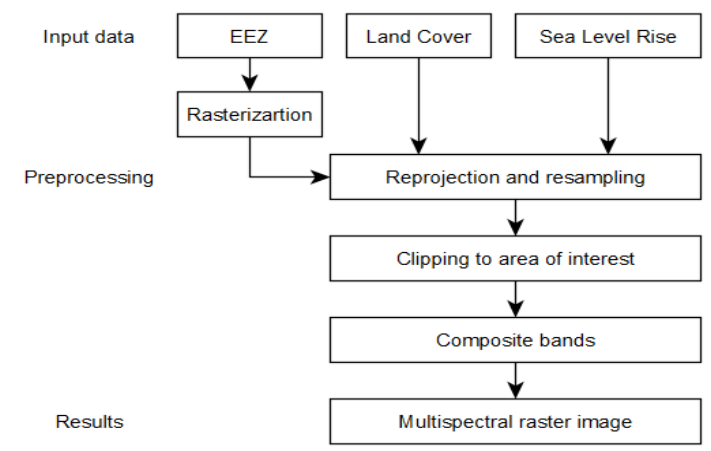

Figure 3: A pre-processing scheme used to create a multiband raster.

After preparing the data, it was possible to conduct relevant operations using the rasterio, numpy and pandas libraries in Python. The multispectral image was 
treated as a 3D numpy matrix and transformed into a pandas DataFrame, where all land cover classes were broken down and calculated by country. The total flooded area was also calculated. The results of the analysis are presented in Section 3.

\subsection{Software and Data Availability}

Research data supporting this publication are available through an Open Science Framework repository (OSF.io 2021).

GlobCover 2009 data is available from the project website (European Space Agency, 2009). Exclusive economic zones data and downloaded manually from MarineRegions.org (Marine Regions, 2021). Data on sea level rise have been acquired for a value of 1 meter from the Center for the Remote Sensing of ICE Sheets (2021). All data was obtained on April 30, 2020.

The computational workflow of this publication is executed via ArcGIS Model Builder workflow and Python SLRAnalysis.py script. The detailed instructions are included in the file README.md in the OSF repository.

\section{Results}

The calculations showed that the countries most at risk from rising sea levels in the region are Brunei $(15.8 \%$ of the country's total area), Indonesia $(8.1 \%$ of the country's total area) and Vietnam (7\% of the country's total area), as shown in Figure 4. While the percentage analysis can give a quick overview of the ratio of inundation for each country, it would be safer to acknowledge the area in square kilometres to have a clear idea of the actual flooding. The $16 \%$ for Brunei may be a much larger ratio compared to the $1 \%$ of Philippines, but in terms of absolute land extent it may be the opposite. More specifically, $154,495 \mathrm{~km}^{2}$ of the coastal area in Indonesia might be flooded by 2100, $26,877 \mathrm{~km}^{2}$ in Vietnam, $13,532 \mathrm{~km}^{2}$ in Malaysia, $3,090 \mathrm{~km}^{2}$ in the Philippines, $1,509 \mathrm{~km}^{2}$ in Thailand, $900 \mathrm{~km}^{2}$ in Brunei, $734 \mathrm{~km}^{2}$ in Myanmar, $195 \mathrm{~km}^{2}$ in Cambodia, $155 \mathrm{~km}^{2}$ in East Timor and $50 \mathrm{~km}^{2}$ in Singapore. Hence, Indonesia, Vietnam and Malaysia are the countries with the highest loss in terms of coastal area extent. Fig. 6 shows a map presenting the areas at risk of sea level rise in the region.

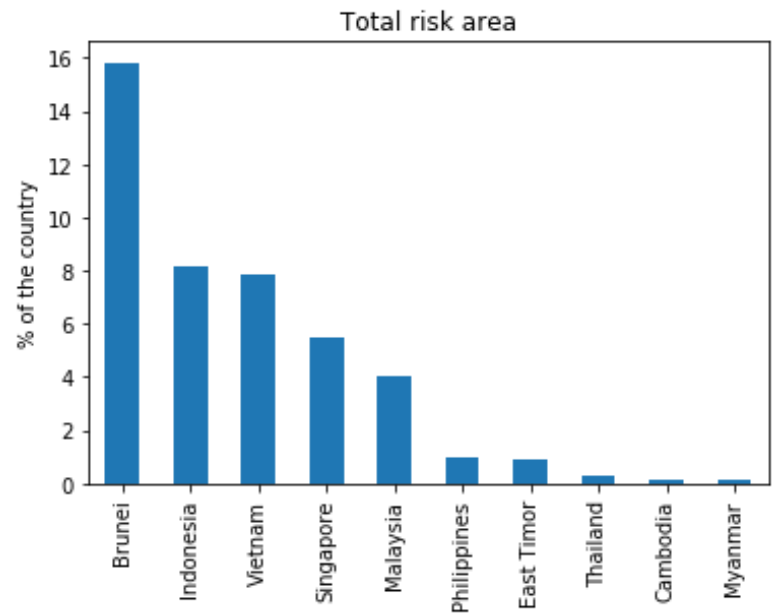

Figure 4: The ratio of areas at risk of sea level rise to the total area of countries.

Then, the total area at risk of sea level rise was calculated by land cover classes adopted according to the GlobCover project classification presented in Tab. 1. The analysis showed that the classes most susceptible to rising sea level are broadleaved forest or shrubland permanently flooded and herbaceous vegetation. As sea levels rise, their share may even fall of 60.4 and $16.2 \%$, respectively, relative to all land in this class. More attention should be paid to urban areas due to the concentration of population since the effects of sea level rise are not limited to the land itself but also to the people living there. Many cities have developed in coastal areas like Jakarta, Singapore or Manila, so the consequences of sea level rise can affect a big share of the future population. As mentioned before, the urban areas are going to face a loss of $10 \%$ in the whole Southeast Asia which corresponds to $674.4 \mathrm{~km}^{2}$. More specifically, we calculate a total loss of $36.7 \mathrm{~km}^{2}$ for the Philippines, in Vietnam $3.7 \mathrm{~km}^{2}$, in Thailand $13.7 \mathrm{~km}^{2}$, in Brunei $86.1 \mathrm{~km} 2$, in Indonesia $396.5 \mathrm{~km}^{2}$, in Malaysia $115 \mathrm{~km}^{2}$, in Singapore $22.3 \mathrm{~km}^{2}$ and in East Timor $0.4 \mathrm{~km}^{2}$. At the same time Myanmar and Cambodia will not have any affected urban areas.

For classes which surface decrease exceeding ten percent of the total area, an additional division by country was performed; the results are presented in Fig 5. 

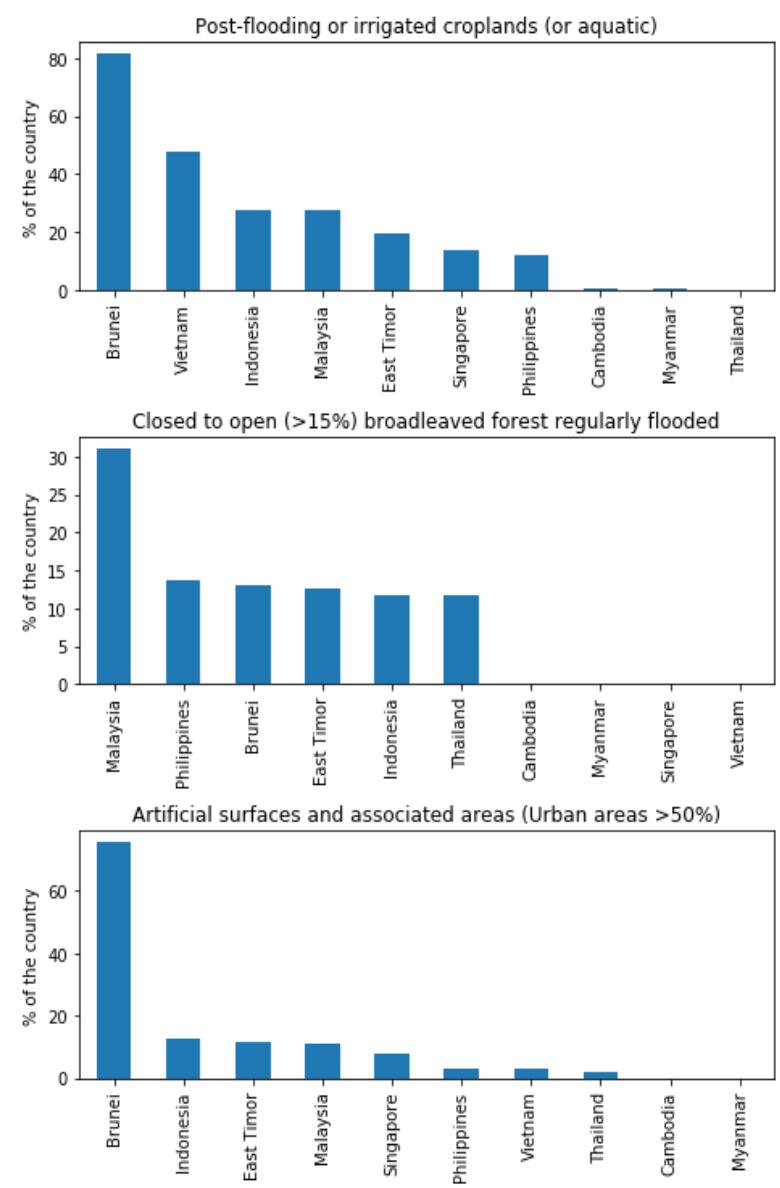

Figure 5: The most threatened classes presented by country.

\section{Discussion}

The study has confirmed that Southeast Asia is particularly vulnerable to sea level rise. The average area at risk for all countries in the region is 4.4 percent. Analysing this in the context of specific land cover classes, the most endangered classes are:

- Post-flooding or irrigated croplands (or aquatic) ${ }^{1}$

- Closed to open (>15\%) herbaceous vegetation (grassland, savannas or lichens / mosses)

- Closed to open ( $>15 \%$ ) broadleaved forest regularly flooded

- Closed (>40\%) broadleaved forest or shrubland permanently flooded

- Artificial surfaces and associated areas (Urban areas $>50 \%$ )

\footnotetext{
${ }^{1}$ Flooded croplands are a habitat type remaining in agricultural use despite periodic or permanent flooding, used for the cultivation of, for example, rice or alfalfa.
}
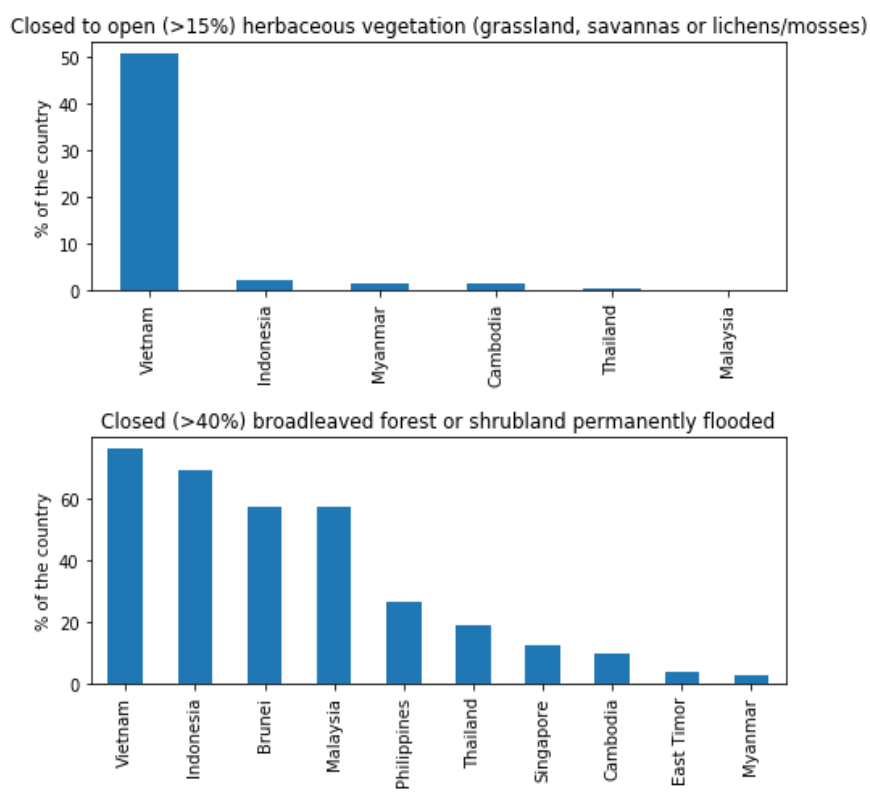

This situation has far-reaching consequences. Over 10 percent of coastal agricultural areas in the region can be flooded by 2100. For Brunei and Vietnam, these figures are 81.4 and 47.9 percent, respectively. In this situation, it is necessary to prepare a long-term policy of conduct by the governments of the countries of the region. One of the potential solutions is the adoption of a retreat policy and the slow relocation of arable land to higher areas, combined with an increase in production efficiency through automation and fertilization (Kool et al., 2020). In the long run, this will allow food production to be maintained at an appropriate level to feed a growing population. However, this will be at the expense of other areas, probably humid tropical forests with their unique flora and fauna (Woodroffe, 1990).

In addition to impacts on long-term food production, rising sea levels mean that over 60 percent of all coastal forests in the region can be irretrievably lost, along with their unique flora and fauna, and for Vietnam this percentage is even higher, at 76.1 percent. In the longterm policy of the countries of the region, it will be necessary to find solutions and funds to protect these 
unique areas. Unfortunately, environmental awareness in the region is still relatively low and it may turn out that international support for regional governments in planning ecological policy and support from foreign funds will be necessary (Paw et al., 1991). region, mainly through the transfer of vulnerable inhabitants to cities and support of urbanization processes. On the one hand, this may increase the pace of development of these countries, but it may also lead to decrease of the standard of living in cities not

\begin{tabular}{|c|c|c|}
\hline Value & Class & $\%$ at risk \\
\hline 11 & Post-flooding or irrigated croplands (or aquatic) & 10.5 \\
\hline 14 & Rainfed croplands & 3.1 \\
\hline 20 & Mosaic cropland (50-70\%) / vegetation (grassland/shrubland/forest) (20-50\%) & 4.7 \\
\hline 30 & Mosaic vegetation (grassland/shrubland/forest) $(50-70 \%) /$ cropland (20-50\%) & 3.7 \\
\hline 40 & Closed to open $(>15 \%)$ broadleaved evergreen or semi-deciduous forest $(>5 \mathrm{~m})$ & 4.4 \\
\hline 50 & Closed $(>40 \%)$ broadleaved deciduous forest $(>5 \mathrm{~m})$ & 0.2 \\
\hline 60 & Open $(15-40 \%)$ broadleaved deciduous forest/woodland $(>5 \mathrm{~m})$ & 0.2 \\
\hline 70 & Closed $(>40 \%)$ needleleaved evergreen forest $(>5 \mathrm{~m})$ & 0.8 \\
\hline 100 & Closed to open $(>15 \%)$ mixed broadleaved and needleleaved forest $(>5 \mathrm{~m})$ & 5.9 \\
\hline 110 & Mosaic forest or shrubland (50-70\%) / grassland (20-50\%) & 6.1 \\
\hline 120 & Mosaic grassland (50-70\%) / forest or shrubland (20-50\%) & 7.5 \\
\hline 130 & Closed to open ( $>15 \%)$ (broadleaved or needleleaved, evergreen or deciduous) shrubland & 1.7 \\
\hline 140 & Closed to open (>15\%) herbaceous vegetation (grassland, savannas or lichens/mosses) & 16.2 \\
\hline 150 & Sparse $(<15 \%)$ vegetation & 1.5 \\
\hline 160 & Closed to open (>15\%) broadleaved forest regularly flooded & 12.3 \\
\hline 170 & Closed $(>40 \%)$ broadleaved forest or shrubland permanently flooded & 60.3 \\
\hline 190 & Artificial surfaces and associated areas (Urban areas $>50 \%$ ) & 10.1 \\
\hline 200 & Bare areas & 2.7 \\
\hline
\end{tabular}

Table 1: Table presenting the ratio of the areas at risk to the total area of each class.

Finally, densely populated urban areas, particularly at risk in countries such as Brunei (75.5\% of all areas), Indonesia (12.7\% of all areas), East Timor $(11.5 \%$ of all areas) and Malaysia (10.8\% of all areas) will require significant efforts to protect them against the effects of sea level rise or massive population movements to higher areas. This situation can develop in different ways. Migration can take place in an organized or an unorganized manner. In the first case, governments will consciously move the population, selecting areas for withdrawal and areas to be protected. The threat to this solution is the relocation of ethnic and national minorities for faster assimilation. However, this will allow for a conscious relocation of the population and support in this process. The second option is unsynchronized migration, which is more democratic, but can lead to overpopulation of some areas and the creation of slums. Such migration may also lead to a change in the social structure of the countries of the prepared for such number of additional inhabitants. Finally, such migrations can cause further stratification of social classes and lead to unrest in the countries of the region, and in the long run even to interstate conflicts. It is also worth noting that our calculations are based on the current land cover; however, changes in population, among other developments, will undoubtedly change land cover patterns in South-East Asia over the next decades.

All this presents a huge challenge for the countries of the region and requires them to have a long-term policy of preventing or mitigating the effects of rising sea levels. 


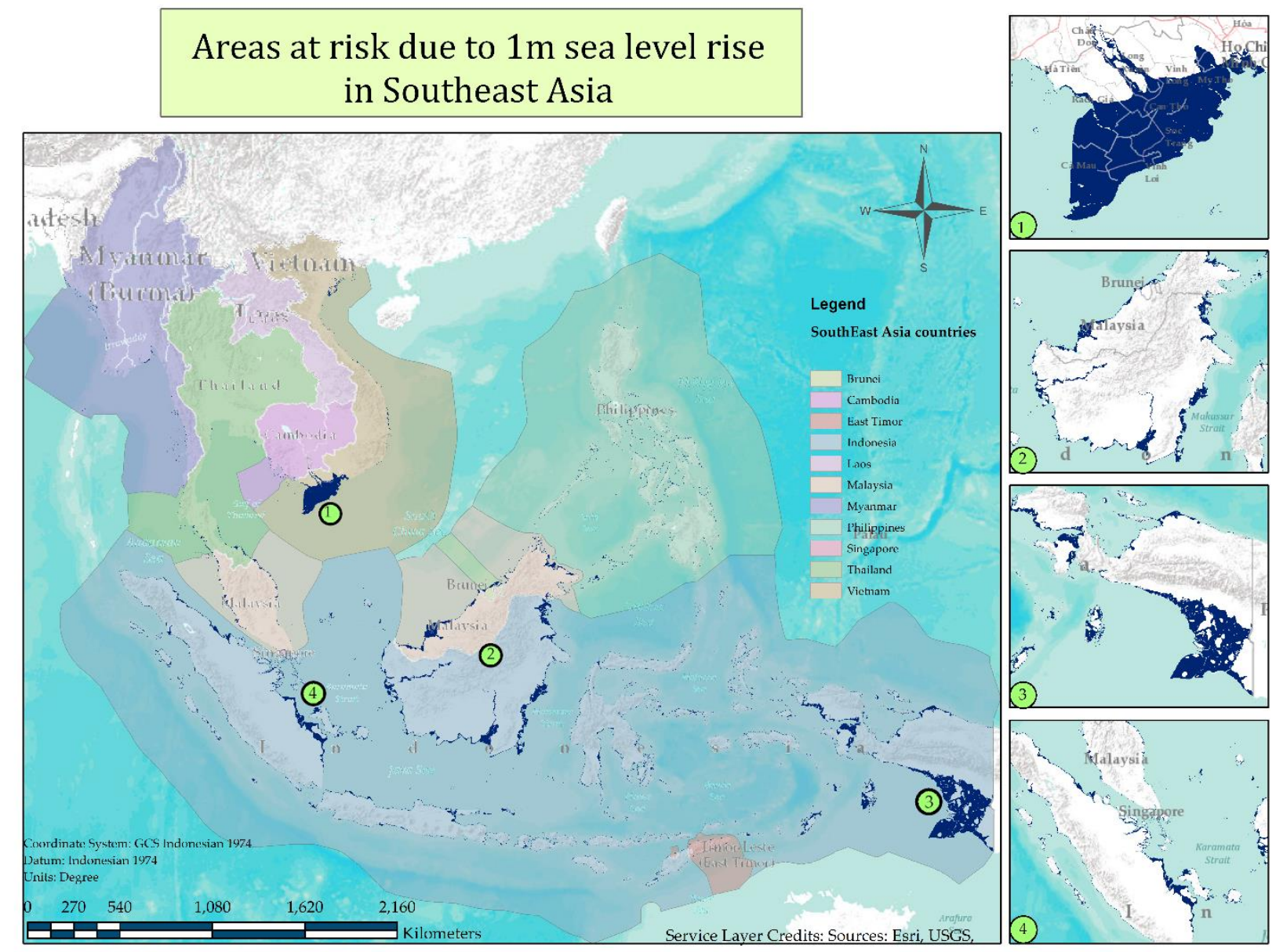

Figure 6: Areas at risk due to 1m sea level rise in Southeast Asia. Center For Remote Sensing Of Ice Sheets (2021).

Knowledge about how the structure of the land cover will change after the sea level rises is therefore necessary to be able to plan these policies correctly.

The next step in the research will be the analysis of various sea level rise scenarios as well as the time analysis of these changes. This will allow a better understanding of the processes that may take place in South-East Asia in the coming decades.

\section{References}

Abidin, Hasanuddin Z. \& Andreas, Heri \& Gamal, Mai \& Gumilar, Irwan \& Napitupulu, Maurits \& Fukuda, Yoichi \& Deguchi, T. \& Maruyama, Y \& Riawan, Edi. (2010). Land subsidence characteristics of the Jakarta basin (Indonesia) and its relation with groundwater extraction and sea level rise. 10.1201/b10530-11.

Bollmann, Moritz and et, al (2010) World Ocean Review: Living with the oceans. Hamburg, Germany, Maribus GmbH https://cresis.ku.edu/content/research/maps?qtsea_level_rise_maps=9\#qt-sea_level_rise_maps

Chen, Chi-Chung \& McCarl, Bruce \& Chang, ChingCheng. (2012). Climate change, sea level rise and rice: Global market implications. Climatic Change. 110. 543560. 10.1007/s10584-011-0074-0.

David, Laura \& Maneja, Rommel \& Goh, Beverly \& Lansigan, Felino \& Pich, Sereywath \& Radjawane, Ivonne \& Matsumoto, Bernardette \& Tantichodok, Pitiwong \& Snidvong, Anond \& Tri, Nguyen \& Nguyen, Kim \& Saito, Yoshiki \& Hinkel, Jochen. (2008). Sea Level Rise Vulnerability of Southeast Asian Coasts. INPRINT ISSN 2070-2000. 2008. 3-6.

Due.esrin.esa.int. (2020). ESA Data User Element. [online] Available at: <http://due.esrin.esa.int/page_globcover.php> [Accessed 6 May 2020].

Esri.com. (2020). About Arcgis | Mapping \& Analytics Platform. [online] Available at: $<$ https://www.esri.com/en-us/arcgis/aboutarcgis/overview> [Accessed 3 May 2020]. 
European Space Agency (2009) Glob Cover Land Cover Maps: http://due.esrin.esa.int/page_globcover.php

International Monetary Fund, "Report for Selected Countries and Subjects". World Economic. Outlook Database, October 2016

Katsman, C.A., Sterl, A., Beersma, J.J. et al. Exploring high-end scenarios for local sea level rise to develop flood protection strategies for a low-lying delta-the Netherlands as an example. Climatic Change 109, 617645 (2011). https://doi.org/10.1007/s10584-011-0037-5

Kool, Rick \& Lawrence, Judy \& Drews, Martin \& Bell, Rob. (2020). Preparing for Sea-Level Rise through Adaptive Managed Retreat of a New Zealand Stormwater and Wastewater Network. Infrastructures. 5. 92. 10.3390/infrastructures5110092.

Marine Regions (2021). Marine Regions: http://www.marineregions.org

Mehvar, S., Filatova, T., Syukri, I., Dastgheib, A. and Ranasinghe, R., 2018. Developing a framework to quantify potential Sea level rise-driven environmental losses: A case study in Semarang coastal area, Indonesia. Environmental Science \& Policy, 89, pp.216230.

OSF.io, 2021: Sea Level Rise in Southeast Asia: https://osf.io/6nfk4/?view_only=cb35ab958bf0410db3 $\underline{60 f 5 c b f b d 67 a 33}$

Rahmstorf, S., Perrette, M. \& Vermeer, M. Testing the robustness of semi-empirical sea level projections. Clim $\begin{array}{llll}\text { Dyn } & 39, & 861-875 & \text { (2012). }\end{array}$ https://doi.org/10.1007/s00382-011-1226-7

Sterr, H., 2008. Assessment of Vulnerability and Adaptation to Sea-Level Rise for the Coastal Zone of Germany. Journal of Coastal Research, 242, pp.380393.

Thomsen, Dana C.; Smith, Timothy F.; Keys, Noni (2012). "Adaptation or Manipulation? Unpacking Climate Change Response Strategies". Ecology and Society. 17 (3). doi:10.5751/es-04953-170320

Woodroffe C. D. The impact of sea-level rise on mangrove shorelines. Progress in Physical Geography: Earth and Environment. 1990;14(4):483-520. doi:10.1177/030913339001400404 